Research Paper

\title{
Cerebrospinal Fluid Proteins Identification Facilitates the Differential Diagnosis of Central Nervous System Diffuse Large B Cell Lymphoma
}

\author{
Wen Zheng, YuQin Song, Yan Xie, NingJing Lin, MeiFeng Tu, WeiPing Liu, LingYan Ping, ZhiTao Ying,
} Chen Zhang, LiJuan Deng, XiaoPei Wang, YouYong Lu, Jun Zhu ${ }^{\bowtie}$

Key laboratory of Carcinogenesis and Translational Research (Ministry of Education), Department of Lymphoma, Peking University Cancer Hospital \& Institute. No. 52 Fucheng Road, Haidian District Beijing 100142, China.

$\triangle$ Corresponding author: Prof. Jun Zhu (zhu-jun@bjcancer.org), Department of Lymphoma, Peking University Cancer Hospital \& Institute. No. 52 Fucheng Road, Beijing, China, Tel: (+86-13910333346)

(C) Ivyspring International Publisher. This is an open access article distributed under the terms of the Creative Commons Attribution (CC BY-NC) license (https://creativecommons.org/licenses/by-nc/4.0/). See http://ivyspring.com/terms for full terms and conditions.

Received: 2017.03.26; Accepted: 2017.08.06; Published: 2017.10.09

\begin{abstract}
Background: Diagnosis of central nervous system (CNS) lymphoma remains a challenge. This study aimed to identify cerebrospinal fluid (CSF) proteins that distinguish patients with and without CNS lymphoma. Methods: We used one-dimensional SDS-polyacrylamide gel electrophoresis coupled with liquid chromatography- electrospray ionization-quadrupole-time of flight-mass spectrometry (LC-ESI-Q-TOF MS) to identify CSF proteins in CNS diffuse large B cell lymphoma (DLBCL) patients and controls. Results: Approximately 166 CSF proteins were identified, 12 for the first time in the CSF of lymphoma patients. Three proteins with significantly increased expression in CNS lymphoma patients compared with controls - haemopexin, apolipoprotein Al, and transferrin were verified by immunohistochemistry, and found to be strongly expressed in CNS DLBCL and nodal DLBCL. These proteins were found to be localized in the cytoplasm of a human DLBCL cell line by indirect immunofluorescence. ELISA confirmed expression at higher concentrations in the CSF of CNS lymphoma patients. CSF haemopexin, apolipoprotein Al, and transferrin concentrations were detected in CNS lymphoma patients and had diagnostic sensitivities of $80 \%, 83 \%$, and $70 \%$, and specificities of $75 \%, 89 \%$, and $90 \%$, respectively. Conclusion: Our study suggests that CSF proteins may be potential diagnostic biomarker for CNS lymphoma, especially for patients in which imaging and cytology do not provide a clear diagnosis.
\end{abstract}

Key words: Central nervous system, Lymphoma, Diagnosis, Cerebrospinal fluid, proteins.

\section{Introduction}

Central nervous system (CNS) lymphoma is an extranodal lymphoma, which occurs in the brain, leptomeninges, spinal cord, or eyes [1]. CNS lymphoma incidence has increased steadily over the past 30 years and accounts for $1.2 \%-10.4 \%$ of all diffuse large B-cell lymphomas (DLBCL) in the rituximab era [2]. This is a serious and potentially fatal clinical problem in patients with lymphoma, with particularly poor prognosis and a shorter survival time [3].

Diagnosis of CNS lymphoma remains a clinical challenge. At present, diagnosis depends on histopathology of brain or spinal cord biopsies. Stereotactic brain biopsy is a difficult procedure, and associated with a $1.2 \%-7 \%$ risk of haemorrhage and a $10 \%-35 \%$ risk of failure to achieve definitive histologic diagnosis [4]. Some older patients with certain comorbidities or tumours located in deep brain structures are not suitable for brain biopsy. Only $4 \%-12 \%$ of patients with CNS lymphoma are diagnosed by traditional cytomorphology of cerebrospinal fluid (CSF) and magnetic resonance 
imaging (MRI) ${ }^{5}$. Over expression of CSF proteins was found in most lymphoma patients and indicated a poor prognosis $[5,6]$. We therefore sought to identify which proteins increased and could potentially serve as reliable diagnostic markers. We used liquid chromatography-electrospray ionization-quadrupoletime of flight-mass spectrometry (LC-ESI-Q-TOF MS), which has the technological advantages of high resolution, label-free quantification, and detection unknown high-molecular-weight proteins ${ }^{[7]}$.

CSF has several properties that facilitate differential proteomic profiling compared with blood. First, the brain and spinal cord are bathed in CSF, so CSF is in contact with the extracellular space of the brain and spinal cord. Second, because of the blood-brain barrier, CSF is not exposed to the systemic circulation or to multiple organs. Third, CSF volume is approximately $150 \mathrm{ml}$, compared with the 5-1 blood volume ${ }^{4}$. Changes in CSF cytokine and growth factor levels are seen in many neurological diseases ${ }^{[8]}$. For example, apolipoprotein is thought to be correlated with Alzheimer's disease and brain cancer [9]. Rompp et al. found that CSF haemopexin expression was higher in breast cancer patients with leptomeningeal metastasis [10]. Furthermore, Roy et al.[4] identified antithrombin III (ATIII) among the CSF proteins of patients with CNS lymphoma with good accuracy (75\% sensitivity and $98 \%$ specificity), and there was a correlation between elevated CSF ATIII concentration and shorter survival. Therefore, analysis of CSF proteins may facilitate the diagnosis of CNS lymphoma.

The aim of this study was to evaluate the potential diagnostic value of CSF proteins. We used one-dimensional sodium dodecyl sulfate-polyacrylamide gel electrophoresis (1D SDS-PAGE) coupled with LC-ESI-Q-TOF MS to identify CSF proteins. Using this approach, we identified several novel proteins, as well as some previously identified by Roy et al.[4]. Haemopexin, apolipoprotein A1, and transferrin levels differed significantly between groups. These three proteins were further examined by immunohistochemistry, indirect immunofluorescence assay, and enzyme-linked immunosorbent assay (ELISA).

\section{Materials and Methods}

\section{Ethics statement}

All patients gave their written informed consent for their CSF samples and tumour samples to be used for research. This study was approved by the Medical Ethics Committee of Peking University Cancer Hospital and carried out in accordance with approved guidelines.

\section{Patients}

We identified 40 patients who fulfilled the criteria for the study: diagnoses between January 2007 and March 2013 using the WHO classification, pathological diagnosis of DLBCL, $\geq 18$-years-old, and no other signs of immunosuppression. We compared CSF from 10 patients with CNS DLBCL to 10 controls without CNS lymphoma (nodal DLBCL) in mass spectrometry analysis. The 10 CNS DLBCL patients included six cases with primary CNS lymphoma and four cases with secondary CNS lymphoma. We compared CSF from 20 patients with CNS DLBCL to 20 controls without CNS lymphoma (the original 20 plus another 20) in ELISA. Patients classified as having non-CNS lymphoma were so determined by full clinical history, physical examination, CSF analysis and MRI brain examination if necessary. All patients were treated at the Lymphoma Department of Peking University Cancer Hospital. Exclusion criteria were age $<18$ years, HIV positive, and recent therapeutic intervention ( $<3$ weeks). All CSF was from patients with active disease.

\section{CSF specimen collection and cryopreservation}

Forty CSF samples (20 patients with CNS DLBCL and 20 control patients) were collected by lumbar puncture upon first admission and routine examination after informed consent. CSF samples (1 $\mathrm{ml}$ ) were used for routine analysis, including total protein, glucose, cell count, and tumour cell analysis, and another $1 \mathrm{ml} \mathrm{CSF}$ sample was stored at $-80^{\circ} \mathrm{C}$. When performing experiments, CSF samples were thawed at room temperature and used for 1D SDS-PAGE, LC-ESI-Q-TOF MS and ELISA.

\section{ID SDS-PAGE analysis}

Because depletion of high-abundance proteins may result in the loss of meaningful proteins, our study did not deplete CSF albumin and immunoglobulins. CSF samples (40 $\mu$ g protein) were separated by $10 \%$ 1D SDS-PAGE at $60-100 \mathrm{~V}$ for $2-3 \mathrm{~h}$; gels were stained overnight with Coomassie Brilliant Blue R-250.

\section{LC-ESI-Q-TOF MS identification and quantification}

Identification and quantification of differentially expressed CSF proteins used 1D SDS-PAGE followed by LC-ESI-Q-TOF MS (Bruker Daltonics, Bremen, Germany). Protein samples were digested in gel for 24 $\mathrm{h}$ at $37^{\circ} \mathrm{C}$ with an appropriate volume of trypsin solution. Digests were then injected into the LC-ESI-Q-TOF MS system, and proteins were identified and assayed by label-free quantification. The resulting data were processed with MASCOT 
software (Matrix Science, Boston, MA, USA).

\section{Evaluation by immunohistochemical staining}

We validated the proteins detected and their associated biological pathways by literature review, and selected three CSF proteins (haemopexin, apolipoprotein A1 and transferrin) as candidate biomarkers. Eighteen tissue samples used for analyses included six cases with nodal diffuse large B cell lymphoma (NDLBCL), six cases with primary CNS DLBCL, and six cases with normal lymph nodes.

Immunohistochemical staining involved a standard technique with the avidin-biotinylated peroxidase complex method. Apolipoprotein A1 antibody was diluted at 1:100 (Abcam, USA). Haemopexin and transferrin antibody were diluted at 1:200 (Abcam, USA). For each biomarker, images were scored visually by two pathologists, with more than $10 \%$ stained cells defined as positive. The degree of reactivity with each section was scored as the product of the scores for the intensity and extent of staining. The intensity of immunoreactivity was graded $0-3+$ for no staining, weak, medium, and strong staining, respectively.

\section{Evaluation by indirect immunofluorescence}

Haemopexin, apolipoprotein A1, and transferrin were localized by indirect immunofluorescence in a human DLBCL cell line (SU-DHL-16). The cell concentration was adjusted to $3 \times 10^{6} / \mathrm{ml}$ in RPMI 1640 and cells were incubated at $20^{\circ} \mathrm{C}$ for $2 \mathrm{~h}$ with antibodies to haemopexin, apolipoprotein A1, and transferrin. Staining was visualized using rhodamine labelled goat anti-rabbit IgG at $20^{\circ} \mathrm{C}$ for $1 \mathrm{~h}$ and Hoechst33342. Images were obtained by confocal laser scanning microscopy.

\section{Evaluation by ELISA}

We use an enzyme-linked immunosorbent assay (ELISA) kit with pre-coated plates (Abcam, USA), to detect expression differences of haemopexin, apolipoprotein A1, and transferrin in 40 patients (20 cases with and 20 cases without CNS DLBCL) according to the manufacturers' instructions.

\section{Statistical analysis}

SAS 9.2 (Cary, NC, USA) was used to perform statistical analyses. Unpaired two-tailed $t$-tests were used for group comparisons of haemopexin, apolipoprotein A1, and transferrin after verifying the normality and homogeneity of variance. Data are presented as the mean \pm standard deviation. A two-tailed chi-squared test $\left(X^{2}\right)$ or Fisher's exact test was used to evaluate the difference in clinicopathological factors or routine CSF tests between the CNS lymphoma and control (non-CNS lymphoma) groups. Receiver operating characteristics (ROC) curves were used to evaluate diagnostic efficiency. A p-value $<0.05$ was considered significant.

\section{Results}

\section{The clinical and pathological features of $\mathbf{2 0}$ patients with DLBCL}

CSF samples from 20 patients with DLBCL were examined by LC-ESI-Q-TOF MS. Of these, 10 cases were CNS lymphoma (six cases with primary and four cases with secondary CNS lymphoma), and 10 cases were non-CNS lymphoma. The twenty patients consisted of 10 males and 10 females with a median age of 44.5 years (range 20-71 years) (Table 1 ).

Table 1. Clinical features of 10 patients with CNS lymphoma and 10 patients with non-CNS lymphoma

\begin{tabular}{|c|c|c|c|}
\hline Item & $\begin{array}{l}\text { CNS lymphoma } \\
\text { Number (\%) }\end{array}$ & $\begin{array}{l}\text { non-CNS lymphoma } \\
\text { Number }(\%)\end{array}$ & $P$ value \\
\hline All & $10(100)$ & $10(100)$ & \\
\hline \multicolumn{4}{|l|}{ Gender } \\
\hline Male & $5(50)$ & $5(50)$ & \\
\hline Female & $5(50)$ & $5(50)$ & 1.000 \\
\hline \multicolumn{4}{|l|}{ Age } \\
\hline$<60$ & $8(80)$ & $8(80)$ & \\
\hline$\geq 60$ & $2(20)$ & $2(20)$ & 1.000 \\
\hline \multicolumn{4}{|c|}{ An Arbor } \\
\hline I-II & $\mathrm{NO}^{*}$ & $2(20)$ & \\
\hline III-IV & $4(40)$ & $8(80)$ & NS \\
\hline \multicolumn{4}{|c|}{ B symptoms } \\
\hline Yes & $2(20)$ & $4(40)$ & \\
\hline No & $8(80)$ & $6(60)$ & 0.629 \\
\hline \multicolumn{4}{|l|}{ IPI } \\
\hline $0-1$ & $2(20)$ & $6(60)$ & \\
\hline$\geq 2$ & $8(80)$ & $4(40)$ & 0.170 \\
\hline \multicolumn{4}{|c|}{$\begin{array}{l}\text { Bone marrow } \\
\text { involvement }\end{array}$} \\
\hline Yes & $0(0)$ & $0(0)$ & \\
\hline No & $10(100)$ & $10(100)$ & NS \\
\hline \multicolumn{4}{|c|}{$\begin{array}{l}\text { Brain CT or MRI } \\
\text { change }\end{array}$} \\
\hline Yes & $9(90)$ & th & \\
\hline No & $1(10)$ & 㶦 & NS \\
\hline
\end{tabular}

\section{CSF total protein content increased in patients with CNS DLBCL}

Routine CSF analysis included the measurement of total and qualitative protein, glucose and nucleated cells, and tumour cell analysis. Notably, CSF protein was elevated in 9/10 patients with CNS DLBCL. Tumour cells were positive in only $3 / 10$ patients with CNS lymphoma. CSF protein was not elevated in non-CNS lymphoma, with tumour cells positive in only one patient out of the 10 (Table 2). The patient was shown not to have CNS lymphoma by another 
two rounds of CSF analysis (on the third and sixth days), MRI brain investigation, and clinical follow-up. The cytological test results for this patient were considered false-positive for CNS DLBCL. These results overall suggest that new approaches are needed to facilitate CNS DLBCL diagnosis.

\section{Identification of CSF proteins differentially expressed in patients with and without CNS DLBCL}

To reduce the variation between individual samples, 20 CSF samples were combined and divided into four aliquots (two with and two without CNS lymphoma), and subjected to 1D SDS-PAGE (Figure $1)$. The observed protein molecular masses were mainly between 25 and $170 \mathrm{kDa}$. Four gel bands were cut into 44 slices, digested with trypsin, and the digests injected into the LC-ESI-Q-TOF MS system. The experiment was performed with two bioreplicates. Fold-change (FC, no-CNS lymphoma vs. CNS lymphoma) cutoffs of $>1.5$ (or $<0.667$ ) and p-values of $<0.05$ were used as a combined threshold to define biologically relevant proteins. Statistical evaluation was performed using Student's $t$-test for comparing two value sets.

Mass spectrometry data were searched against the MASCOT database, and 166 proteins were identified with a range of expression levels. Several proteins were present in different isoforms or with different post-translational modifications, and detected in multiple spots. The 30 differentially expressed proteins are shown in Table 3. These 30 proteins included nineteen with higher and eleven with lower expression in CNS lymphoma patients compared with control subjects. Twelve of the proteins identified have not previously been described in the CSF of CNS lymphoma patients. These proteins included a-1 antitrypsin and heat shock protein 105 . Mass spectrometry analysis revealed elevated haemopexin, apolipoprotein A1, and transferrin expression in CNS DLBCL. Figure 2 shows spectra including multiple charged species of all three proteins.

Table 2. Cerebrospinal fluid (CSF) features of 10 patients with CNS lymphoma and 10 patients with non-CNS lymphoma

\begin{tabular}{llll}
\hline Item & $\begin{array}{l}\text { CNS lymphoma } \\
\text { Number (\%) }\end{array}$ & $\begin{array}{l}\text { non-CNS } \\
\text { lymphoma } \\
\text { Number }(\%)\end{array}$ & P value \\
\hline $\begin{array}{l}\text { All } \\
\text { Appearance }\end{array}$ & $10(100)$ & $10(100)$ & \\
Abrmal & $8(80)$ & $9(90)$ & 1.000 \\
$\begin{array}{l}\text { Protein qualitative } \\
\text { Negative }\end{array}$ & $2(20)$ & $1(10)$ & \\
$\begin{array}{l}\text { Positive } \\
\text { Total protein }\end{array}$ & $5(50)$ & $10(100)$ & 0.033 \\
Normal & $5(50)$ & $0(0)$ & \\
Increased & $1(10)$ & $10(100)$ & \\
Nucleated cell & $9(90)$ & $0(0)$ & \\
Normal & $8(80)$ & $10(100)$ & 0.474 \\
Increased & $2(20)$ & $0(0)$ & \\
Tumor cell & & $9(90)$ & 0.582 \\
Negative & $7(70)$ & $1(10) *$ & \\
Positive & $3(30)$ &
\end{tabular}

Abbreviations: CNS, central nervous system. *, one of these patients without CNS lymphoma had positive cytology, and was excluded from CNS lymphoma by another 2 times CSF analysis and MRI brain.

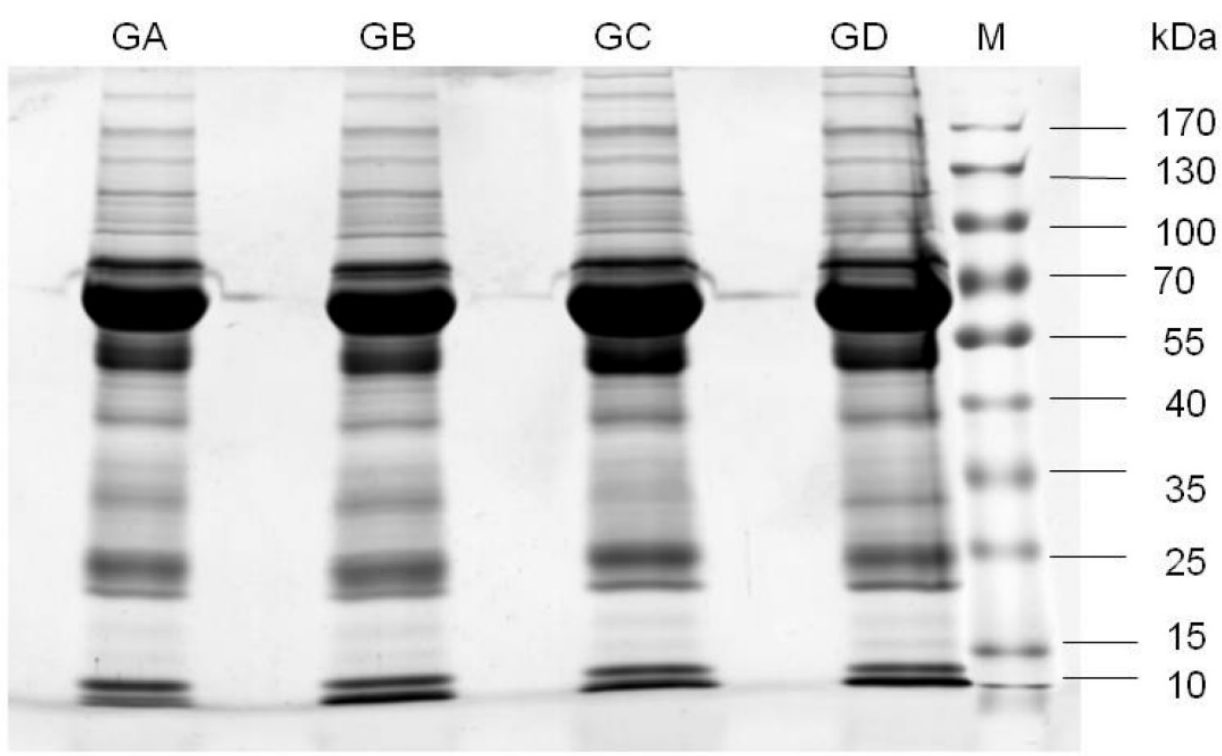

Figure 1. ID-SDS-PAGE gel analysis of CSF samples. Lanes GA and GB are pooled CSF samples from 10 patients with non-CNS DLBCL. Lanes GC and GD are pooled CSF samples from 10 patients with CNS DLBCL. M, prestained protein marker. Observed molecular masses were mainly between 25 and $170 \mathrm{kDa}$. Abbreviations: CNS, central nervous system; DLBCL, diffuse large B cell lymphoma. 
A

Hemopexin

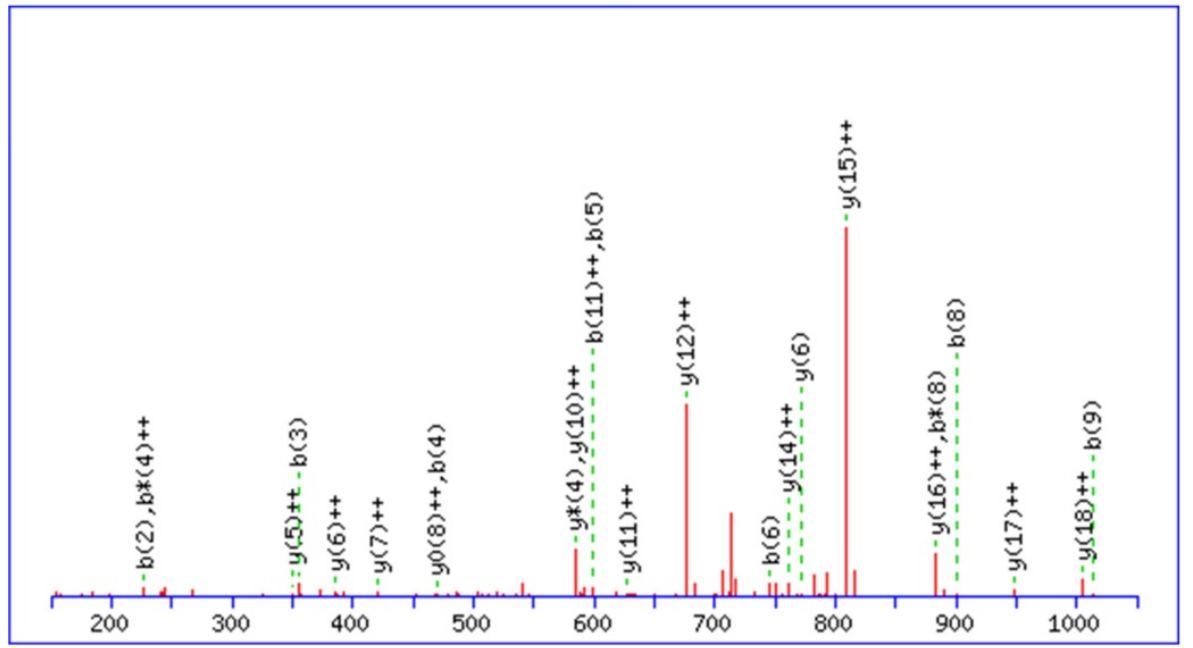

B

Apolipoprotein A1

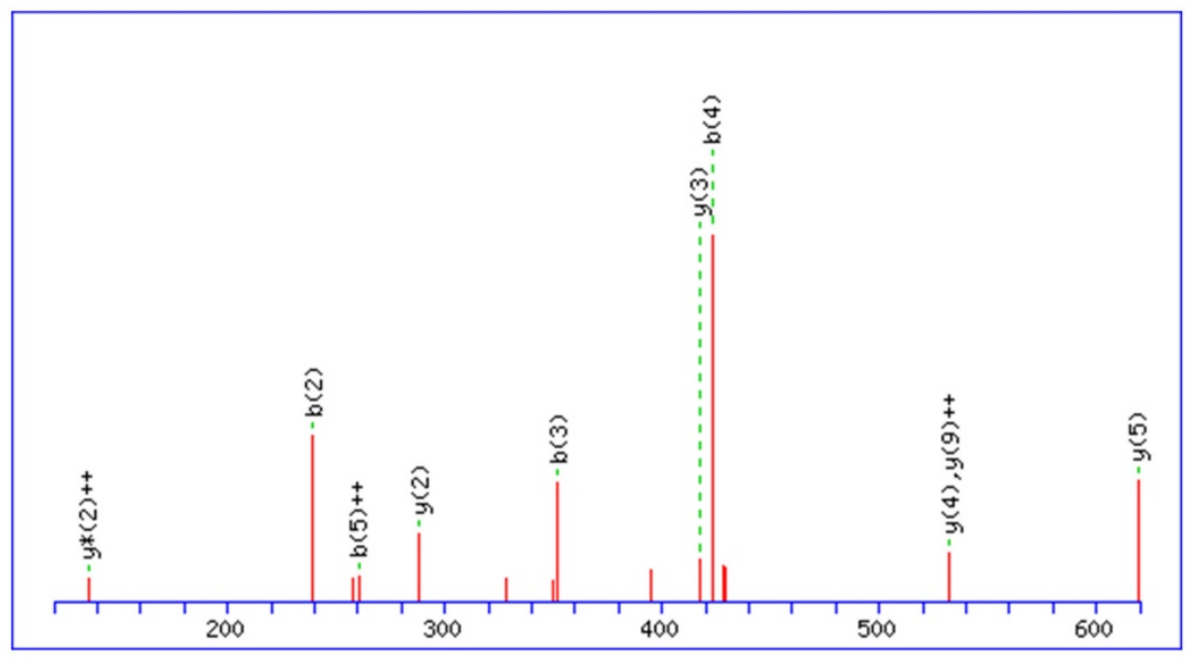

C

\section{Transferrin}

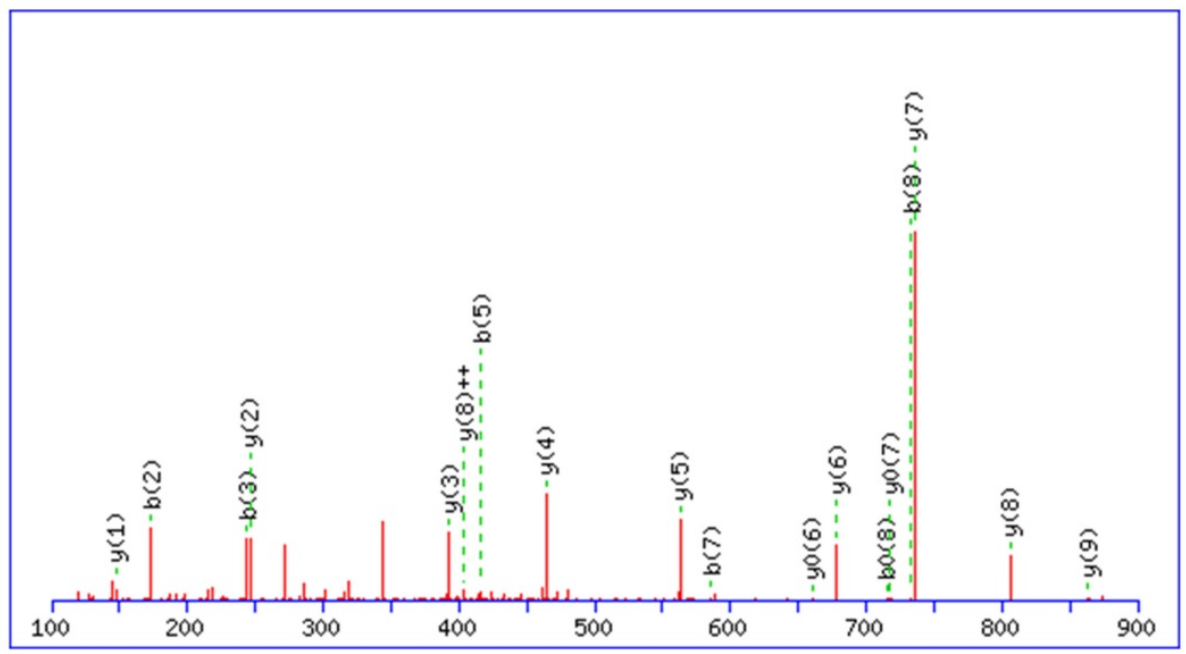

Figure 2. Identification and quantification of CSF proteins by LC-ESI-Q-TOF MS. Haemopexin, apolipoprotein Al, and transferrin expression were elevated in CNS DLBCL relative to non-CNS DLBCL. Spectra showing multiple charged species: (A) haemopexin; (B) apolipoprotein Al; (C) transferrin. Abbreviations: CNS, central nervous system; DLBCL, diffuse large B cell lymphoma. 
Table 3. Cerebrospinal fluid (CSF) proteins differentially expressed in CNS and non-CNS lymphoma

\begin{tabular}{|c|c|c|c|c|c|}
\hline Row & GI NO. & Accession & Protein description & Fold change & MW [kDa] \\
\hline 1 & 112877 & A1AG1_HUMAN & Alpha-1-acid glycoprotein 1 & 0.21 & 23.5 \\
\hline 2 & 112874 & AACT_HUMAN & Alpha-1-antichymotrypsin & 0.3 & 47.6 \\
\hline 3 & 1703025 & A1AT_HUMAN & Alpha-1-antitrypsin & 0.07 & 46.7 \\
\hline 4 & 308153640 & A2MG_HUMAN & Alpha-2-macroglobulin & 0.58 & 163.2 \\
\hline 5 & 112877 & A1AG1_HUMAN & Alpha-1-acid glycoprotein & 0.33 & 23.5 \\
\hline 6 & 28558769 & APLP1_HUMAN & Amyloid-like protein 1 & 3.92 & 72.1 \\
\hline 7 & 113992 & APOA1_HUMAN & Apolipoprotein A-I & 0.21 & 30.8 \\
\hline 8 & 114034 & APOD_HUMAN & Apolipoprotein D & 0.59 & 21.3 \\
\hline 9 & 114039 & APOE_HUMAN & Apolipoprotein E & 1.8 & 36.1 \\
\hline 10 & 50400672 & CRAC1_HUMAN & Cartilage acidic protein 1 & 4.28 & 71.4 \\
\hline 11 & 2497301 & CNTN1_HUMAN & Contactin-1 & 3.03 & 113.2 \\
\hline 12 & 118183 & CYTC_HUMAN & Cystatin-C & 2.83 & 15.8 \\
\hline 13 & 311033372 & DKK3_HUMAN & Dickkopf-related protein 3 & 2.08 & 38.3 \\
\hline 14 & 48429255 & ECM1_HUMAN & Extracellular matrix protein 1 & 2.53 & 60.6 \\
\hline 15 & 20178280 & FIBG_HUMAN & Fibrinogen gamma chain & 0.07 & 51.5 \\
\hline 16 & 215274249 & FBLN1_HUMAN & Fibulin-1 & 1.95 & 77.2 \\
\hline 17 & 122713 & HBD_HUMAN & Hemoglobin subunit delta & 0.08 & 16.0 \\
\hline 18 & 56749856 & HBB_HUMAN & Hemoglobin subunit beta & 0.31 & 16.0 \\
\hline 19 & 1708182 & HEMO_HUMAN & Hemopexin & 0.46 & 51.6 \\
\hline 20 & 113584 & IGHA1_HUMAN & Ig alpha- 1 chain $C$ region & 0.27 & 37.6 \\
\hline 21 & 121039 & IGHG1_HUMAN & Ig gamma- 1 chain $C$ region & 0.46 & 36.1 \\
\hline 22 & 224471888 & FCGBP_HUMAN & IgG Fc-binding protein & 0.27 & 571.6 \\
\hline 23 & 193806374 & IGHM_HUMAN & Ig mu chain $\mathrm{C}$ region & 0.05 & 49.3 \\
\hline 24 & 239938886 & K1C9_HUMAN & Keratin, type I cytoskeletal 9 & 0.27 & 62.0 \\
\hline 25 & 239938650 & K22E_HUMAN & Keratin, type II cytoskeletal 2 epidermal & 0.33 & 65.4 \\
\hline 26 & 85700158 & TRFL_HUMAN & Lactotransferrin & 1.59 & 78.1 \\
\hline 27 & 215274127 & NRCAM_HUMAN & Neuronal cell adhesion molecule & 5.87 & 143.8 \\
\hline 28 & 2494289 & NELL2_HUMAN & Protein kinase C-binding protein NELL2 & 6.72 & 91.3 \\
\hline 29 & 313104271 & TRFE_HUMAN & Serotransferrin & 0.28 & 77.0 \\
\hline 30 & 113576 & ALBU_HUMAN & Serum albumin & 0.29 & 69.3 \\
\hline
\end{tabular}

Abbreviations: CNS, central nervous system; Fold change (no-CNS lymphoma vs CNS lymphoma) cut-offs of $>1.5$ (or $<0.667$ ) and significance p-values of $<0.05$.

\section{Analysis of differentially expressed CSF proteins in CNS lymphoma tissues and cell lines}

We used immunohistochemical staining to confirm expression of haemopexin, apolipoprotein $\mathrm{A} 1$, and transferrin in tissue sections from 18 patients (Figure 3). We found that these three CSF proteins were more strongly expressed in CNS DLBCL and NDLBCL samples relative to the control group, where the expression was low or sometimes negative. Haemopexin showed positive expression in 5/6 CNS lymphomas. These findings suggest a potential novel role for CSF proteins in the initiation and progression of CNS DLBCL.

We further used indirect immunofluorescence to demonstrate positive expression of haemopexin, apolipoprotein A1 and transferrin in the human DLBCL cell line SU-DHL-16. Specific red fluorescence was observed in the plasma by use of an indirect fluorescent antibody (Figure 4).

\section{Expression levels of haemopexin, apolipoprotein A1, and transferrin in CSF are associated with CNS DLBCL}

We next used sandwich ELISA to measure the expression levels of haemopexin, apolipoprotein A1, and transferrin in CSF. CSF concentrations of all three candidate biomarkers were at least two-fold higher in the CNS lymphoma cohort compared with control subjects (p-values $0.002,0.003$, and 0.013 , respectively) (Table 4). The potential utility of haemopexin, apolipoprotein A1 and transferrin in CSF as diagnostic biomarkers for CNS lymphoma was evaluated by ROC curve analysis. The areas under the ROC curves, which give an indication of the sensitivity and specificity of diagnosis using the three CSF proteins, are shown in Table 5. The haemopexin ROC curve indicated that an area under the curve of 0.810 would discriminate CNS from non-CNS lymphoma. A CSF haemopexin cutoff concentration of $32.0 \mathrm{ug} / \mathrm{ml}$ identified CNS lymphoma patients with the highest accuracy ( $80 \%$ sensitivity and $75 \%$ specificity). By contrast, cytological evaluation of CSF in this cohort of twenty CNS lymphoma patients was only $25 \%$ sensitive in the detection of CSF tumour cells.

\section{Discussion}

We used a mass spectrometry-based proteomic approach to perform differential protein identification and quantification in the CSF from patient groups with and without CNS lymphoma. 166 CSF proteins were identified, 30 of which were significantly 
differentially expressed. Of these, 12 have not previously been described in the CSF in CNS lymphoma, including a-1 antitrypsin, heat shock protein 105 , and nesprin-1. $\alpha-1$ Antitrypsin is a serine protease inhibitor and an acute phase reactant. Previous research and clinical findings reported that a deficiency in serum $\alpha-1$ antitrypsin is associated with increased risk of malignant lymphoma [11]. However, we found that $\alpha-1$ antitrypsin was present at a higher level in the CSF from CNS lymphoma patients than in controls. In a prospective study, Bujanda et al.[12] found that $\alpha-1$ antitrypsin was the most useful serum marker for early stage colorectal cancer diagnosis. A report on paediatric Hodgkin's lymphoma showed that serum $\alpha-1$ antitrypsin expression correlated with severity [13]. In addition, some research suggests that heat shock protein is over expressed in many cancers and is an attractive therapeutic target ${ }^{[14,15]}$.
Table 4. Expression of haemopexin, apolipoprotein $A 1$, and transferrin in CSF from 20 patients with CNS DLBCL and 20 patients without CNS DLBCL

\begin{tabular}{llll}
\hline Item & $\begin{array}{l}\text { Hemopexin } \\
(\mathrm{ug} / \mathrm{ml})\end{array}$ & $\begin{array}{l}\text { apolipoprotein A1 } \\
(\mathrm{ug} / \mathrm{ml})\end{array}$ & $\begin{array}{l}\text { Transferrin } \\
(\mathrm{ug} / \mathrm{ml})\end{array}$ \\
\hline $\begin{array}{l}20 \text { cases with CNS } \\
\text { lymphoma }\end{array}$ & $12.898 \pm 10.165$ & $72.687 \pm 47.256$ & $12.799 \pm 7.492$ \\
$\begin{array}{l}20 \text { cases with } \\
\text { non-CNS }\end{array}$ & $3.764 \pm 2.941$ & $35.979 \pm 16.620$ & $8.181 \pm 2.776$ \\
$\begin{array}{l}\text { lymphoma } \\
\text { P values }\end{array}$ & 0.002 & & \\
\hline
\end{tabular}

Abbreviations: CSF, cerebrospinal fluid; CNS, central nervous system; DLBCL, diffuse large B cell lymphoma.

Table 5. Sensitivity and specificity of haemopexin, apolipoprotein $\mathrm{Al}$, and transferrin of CNS DLBCL

\begin{tabular}{lllll}
\hline Proteins & $\begin{array}{l}\text { Area under the cutoff } \\
\text { ROC curve }\end{array}$ & $\begin{array}{l}\text { Sensitivity } \\
(\mu \mathrm{g} / \mathrm{mL})\end{array}$ & Specificity $(\%)$ \\
\hline $\begin{array}{l}\text { hemopexin } \\
\text { apolipoprotein }\end{array}$ & 0.810 & 32.00 & 80.0 & 75.0 \\
A1 & 0.899 & 6.623 & 83.3 & 89.5 \\
transferrin & 0.718 & 9.160 & 70.0 & 90.0 \\
\hline
\end{tabular}

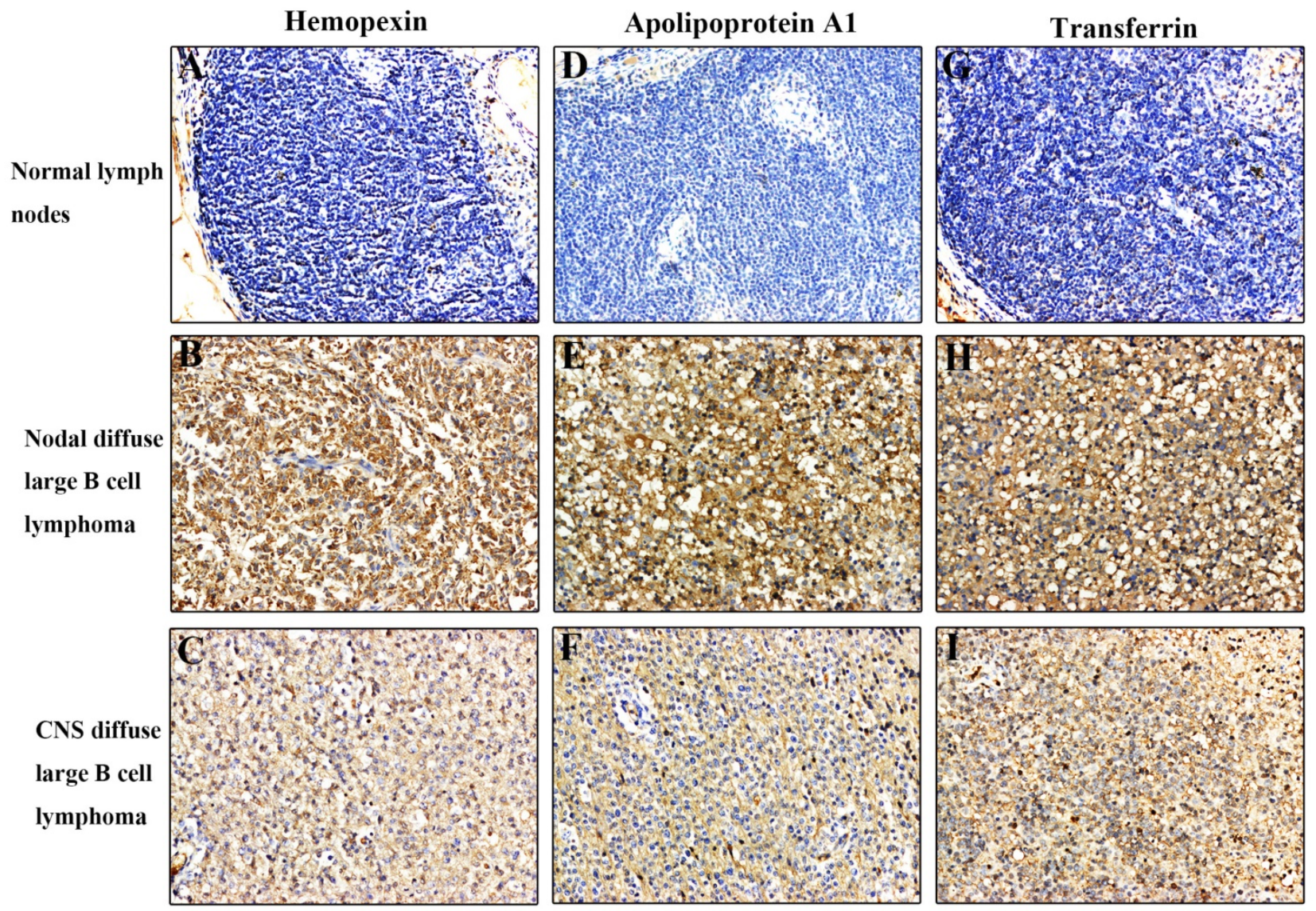

Figure 3. Immunohistochemical analysis of haemopexin, apolipoprotein Al, and transferrin in tissue sections. All three proteins were expressed at higher levels in CNS DLBCL and NDLBCL than in normal tissue. (A) Normal lymph nodes negative for haemopexin; (B) NDLBCL positive for haemopexin; (C) CNS DLBCL positive for haemopexin; (D) Normal lymph nodes negative for apolipoprotein AI; (E) NDLBCL positive for apolipoprotein A1; (F) CNS DLBCL positive for apolipoprotein $\mathrm{Al}$; (G) Normal lymph nodes negative for transferrin; (H) NDLBCL positive for transferrin; (I) CNS DLBCL positive for transferrin. Original magnification $=200 \times$. Abbreviations: $C N S$, central nervous system; DLBCL, diffuse large $B$ cell lymphoma; NDLBCL, nodal diffuse large $B$ cell lymphoma. 

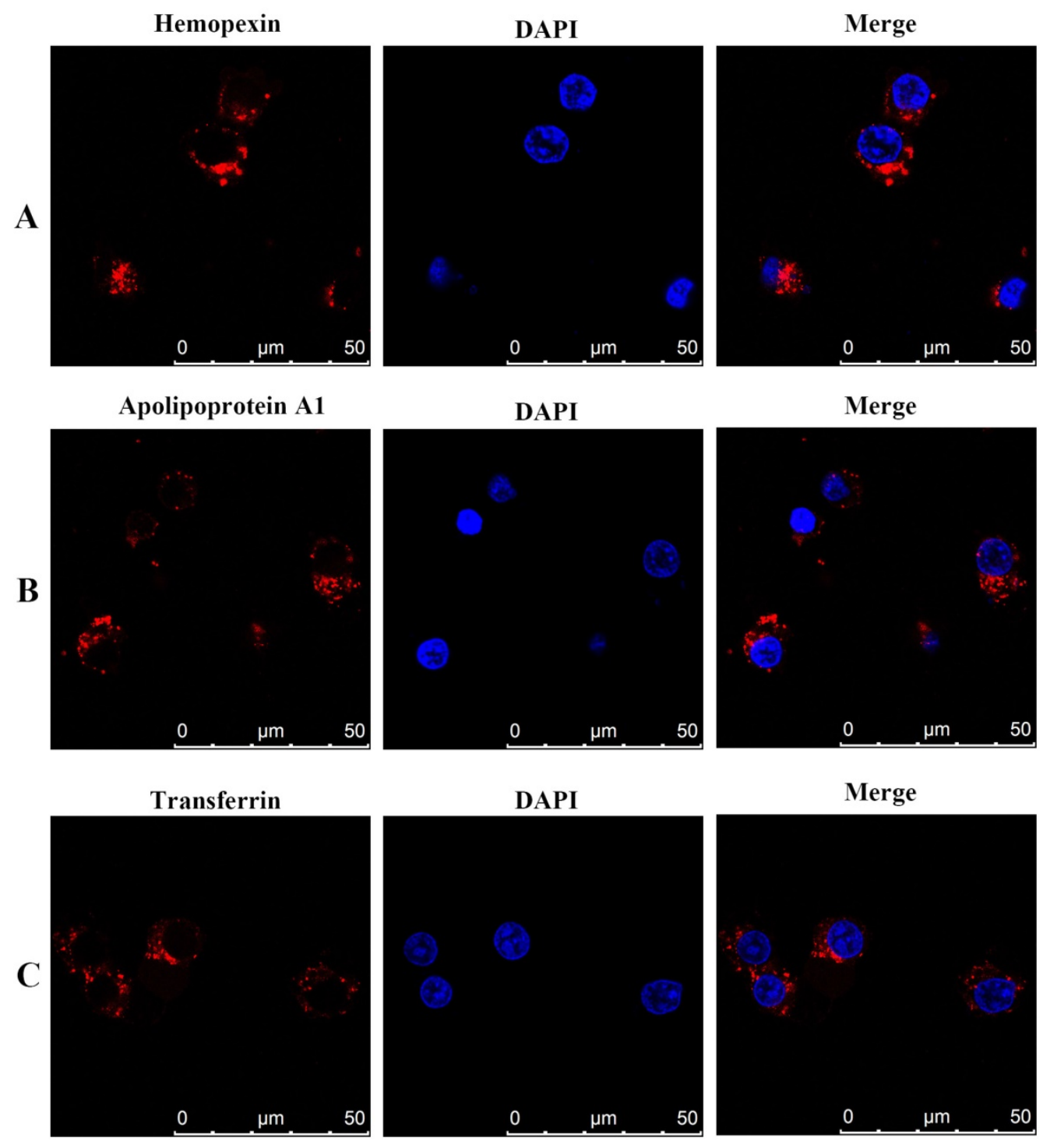

Figure 4. Immunofluorescence staining and confocal microscopy analysis of haemopexin, apolipoprotein A1, and transferrin in human DLBCL SU-DHL-16 cell line treated with various fixatives. Fixed and permeabilized cells were stained with anti-haemopexin, anti-apolipoprotein A1, and anti-transferrin antibody, and rhodamine-conjugated secondary antibody (red). Nuclei were stained with DAPI (blue). In merged figures, haemopexin, apolipoprotein $\mathrm{Al}$, and transferrin appear as bright red fluorescence (red). Abbreviations: CNS, central nervous system; DLBCL, diffuse large B cell lymphoma.

We also identified 22 proteins that had previously been reported in the literature, including low-level expression of normal brain-related proteins such as neuronal cell adhesion molecule and contactin-1, which have been associated with CNS lymphoma [4]. A number of proteins detected at relatively higher levels in the CSF from CNS lymphoma patients have been implicated in tumour invasion, as exemplified by a2-macroglobulin and a1-acid glycoprotein [16]. Immunoglobulin superfamily proteins, including immunoglobulin $\gamma$ and $\alpha$-chains, were also expressed at higher levels in CNS lymphoma, suggesting activation of an immune response.

Through literature review and biological information analysis, three proteins in CSF specimens were selected here for further valuation by immunohistochemistry, indirect immunofluorescent assay, and ELISA. The first candidate biomarker is haemopexin. Rompp et al. found elevated CSF haemopexin expression in breast cancer patients with leptomeningeal metastasis [10]. The second candidate biomarker is apolipoprotein A1, a unique human plasma lipoprotein discovered by Berg in 1963. Traditional research results have shown that elevated lipoprotein A1 levels are linked with a higher risk of atherosclerosis. Recent research has found that it is associated with tissue repair, wound healing, and anticancer effects [17]. Tung et al. found that increased expression levels of plasma apolipoprotein A1 may be associated with progression and development of oral squamous cell carcinoma [18].The third candidate 
biomarker is transferrin, which plays a role in endocytosis and recycling, which are essential for iron uptake and promoting proliferation of lymphoma cells [19]. Rodriquez et al. have identified a drug that blocks transferrin receptor activity, leading to iron deficiency in cells, which may therefore be used to treat lymphomas [20].

Here, the upregulation and localization of haemopexin, apolipoprotein A1, and transferrin were confirmed by immunohistochemistry, indirect immunofluorescent assay and ELISA to better understand their potential clinical significance. Immunohistochemistry showed these three proteins were strongly expressed in patients with CNS DLBCL, and weakly expressed or not detectable in controls without CNS DLBCL. Sandwich ELISA was used to measure expression of all three proteins in 40 patients with DLBCL (20 patients with, and 20 controls without, CNS lymphoma). Results revealed increased expression in the CSF of patients with CNS lymphoma compared with the controls. ROC curve analyses indicated that haemopexin, apolipoprotein $\mathrm{A} 1$, and transferrin in CSF may act as discriminators of CNS lymphoma from non-CNS lymphoma at 0.810 , 0.899 , and 0.718 , respectively. Sensitivity ranged from $70 \%$ to $83 \%$, and specificity ranged from $75 \%$ to $90 \%$. A CSF haemopexin cutoff concentration of $32.0 \mu \mathrm{g} / \mathrm{ml}$ identified CNS lymphoma patients with the highest accuracy ( $80 \%$ sensitivity and $75 \%$ specificity). These results suggest that determination of specific CSF protein concentrations combined with imaging may make possible early diagnosis of patients with suspected CNS lymphoma. The three CSF proteins were located in the lymphoma cell cytoplasm in indirect immunofluorescent assays. It may prove possible to detect changes in these CSF proteins and facilitate early and noninvasive diagnosis. This is also a very interesting. The protein may be expression in CSF and is worth further exploration.

In summary, we used LC-ESI-Q-TOF MS technology to measure differential expression of CSF proteins in CNS DLBCL. We identified 12 proteins that had not previously been described in the CSF of CNS lymphoma patients. We evaluated expression of haemopexin, apolipoprotein A1 and transferrin by immunohistochemistry in patients with DLBCL. We demonstrated that all three proteins localized to the cytoplasm in a human DLBCL cell line. We also used ELISA technology to measure differential expression in patients with and without CNS lymphoma and to explore the clinical significance of the differential expression. Our study suggests that these CSF proteins may be potential diagnostic biomarkers for CNS lymphoma, especially for patients in which imaging and cytology do not provide a clear diagnosis. These discoveries may aid in the acceleration of novel anticancer therapeutics.

\section{Acknowledgements}

The study was financially supported by the Capital Medical Development Research Foundation (No. 2009-3165) and the Capital Health Research and Development of Special (No. 2014-2-2153) in China. We thank J. Shen, H.F. Tian, and Z.H. Tian from Peking University Cancer Hospital \& Institute for their support in carrying out the experiments.

\section{Author Contributions}

Z.W. conceived and designed experiments, collected samples, performed experiments, analysed data, wrote the paper and prepared Figures and Tables. Z.J. and L.Y.Y. designed the experiments and analysed the data. S.Y.Q., X.Y., L.N.J., T.M.F., L.W.P, P.L.Y., Y.Z.T., Z.C., D.L.J., and W.X.P. organised the clinical materials.

\section{Competing Interests}

The authors have declared that no competing interest exists.

\section{References}

1. Baraniskin A, Deckert M, Schulte-Altedorneburg G, et al. Current strategies in the diagnosis of diffuse large B-cell lymphoma of the central nervous system. Br J Haematol.2012; 156(4):421-432.

2. Krmek DZ, Ljubić N, Vrbanić L. Isolated central nervous system relapse of diffuse large B-cell lymphoma in the era of immunochemotherapy. Acta Med Croatica. 2013; 66:403-407.

3. Krawczyk K, Jurczak W, Długosz-Danecka M, et al. Central nervous system prophylaxis with intrathecal liposomal cytarabine in diffuse large B-cell lymphomas. Pol Arch Med Wewn. 2013; 123(11): 589-595.

4. Roy S, Josephson SA, Fridlyand J, et al. Protein biomarker identification in the CSF of patients with CNS lymphoma. J Clin Oncol. 2008; 26(1): 96-105.

5. Zheng W, Lin NJ, Xie $Y$, et al. Central nervous system lymphoma and its significance. Zhonghua Yi Xue Za Zhi. 2011; 91(22): 1550-1554.

6. Rubenstein JL, Gupta NK, Mannis GN, et al. How I treat CNS lymphomas. Blood. 2013; 122(14): 2318-2330.

7. Stanstrup J, Gerlich M, Dragsted LO, et al. Metabolite profiling and beyond: approaches for the rapid processing and annotation of human blood serum mass spectrometry data. Anal Bioanal Chem. 2013; 405(15): 5037-5048.

8. Mashayekhi F, Salehi Z, Jamalzadeh HR. Quantitative analysis of cerebrospinal fluid brain derived neurotrophic factor in the patients with multiple sclerosis. Acta Medica (Hradec Kralove). 2012; 55(2): 83-86.

9. Roher AE, Maarouf CL, Sue LI, et al. Proteomics-derived cerebrospinal fluid markers of autopsy-confirmed Alzheimer's disease. Biomarkers. 2009; 14(7):493-501.

10. Römpp A, Dekker L, Taban I, et al. Identification of leptomeningeal metastasis-related proteins in cerebrospinal fluid of patients with breast cancer by a combination of MALDI-TOF, MALDI-FTICR and nanoLC-FTICR MS. Proteomics. 2007; 7(3):474-481.

11. Sun Z, Yang P. Role of imbalance between neutrophil elastase and alpha 1-antitrypsin in cancer development and progression. Lancet Oncol. 2004; 5(3):182-190.

12. Bujanda L, Sarasqueta C, Cosme A, et al. Evaluation of alpha 1-antitrypsin and the levels of mRNA expression of matrix metalloproteinase 7, urokinase type plasminogen activator receptor and COX-2 for the diagnosis of colorectal cancer. PLoS One. 2013; 8(1):e51810.

13. Qi L, Cazares L, Johnson C, et al. Serum protein expression profiling in pediatric Hodgkin lymphoma: a report from the Children's Oncology Group. Pediatr Blood Cancer. 2008; 51(2): 216-221.

14. Kucine N, Marubayashi S, Bhagwat N, et al. Tumor-specific HSP 90 inhibition as a therapeutic approach in JAK-mutant acute lymphoblastic leukemias. Blood. 2015; 126(22):2479-2483.

15. Hosaka S, Nakatsura $\mathrm{T}$, Tsukamoto $\mathrm{H}$, et al. Synthetic small interfering RNA targeting heat shock protein 105 induces apoptosis of various cancer cells both in vitro and in vivo. Cancer Sci. 2006; 97(7): 623-632. 
16. Lim W, Song G. Discovery of prognostic factors for diagnosis and treatment of epithelial-derived ovarian cancer from laying hens. J Cancer Prev. 2013; 18(3):209-220.

17. Zlatohlávek L, Zídková K, Vrablík M. Lipoprotein (a). Vnitr Lek. 2007; 53(4): 434-440.

18. Tung CL, Lin ST, Chou HC, et al. Proteomics-based identifi,ation of plasma biomarkers in oral squamous cell carcinoma. J Pharm Biomed Anal. 2013; 75:7-17.

19. Shakor AB, Taniguchi M, Kitatani $K$, et al. Sphingomyelin synthase 1-generated sphingomyelin plays an important role in transferrin trafficking and cell proliferation. J Biol Chem. 2011; 286(41):36053-36062.

20. Rodríguez JA, Luria-Pérez R, López-Valdés HE, et al. Lethal iron deprivation induced by non-neutralizing antibodies targeting transferrin receptor 1 in malignant B cells. Leuk Lymphoma. 2011; 52(11): 2169-2178. 